Poster Section

\title{
Evaluation of biological activities of highly diluted nucleotide sequences by using cellular models
}

\author{
Etienne Capieaux¹, Ghada Alsaleh², Chloé Borde ${ }^{3}$, Dominique Wachsmann², \\ Vincent Maréchal ${ }^{3}$, Pierre Dorfman ${ }^{1}$
}

\author{
${ }^{1}$ Labo'Life, Gembloux, Belgium \\ ${ }^{2}$ Laboratoire Physiopathologie des Arthrites, Université de Strasbourg, Illkirch, France \\ ${ }^{3}$ Centre de Recherche des Cordeliers, Université Pierre et Marie Curie, Paris, France
}

\begin{abstract}

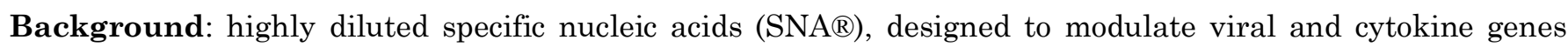
expression, are currently used in Micro-Immunotherapy to treat viral infections and immune disorders. Although some preliminary studies have showed clinical benefit of these homeopathic preparations [1], no experimental data are available to explain their mechanism of action.
\end{abstract}

Aims: to investigate the in vitro effect of two sets of highly diluted (HD) SNA targeting i) latent/lytic EpsteinBarr virus (SNA EBV) and ii) TNF- $\alpha$ and its receptor p55 involved in rheumatoid arthritis (SNA RA) on cellular models.

Methodology: serial homeopathic dilutions of SNA EBV and SNA RA (15cH-18cH) were tested on a EBVpositive B-lymphoblastoid (B95-8) and on a LPS-stimulated macrophage (THP1) cell lines respectively, in comparison with agitated/diluted water and scramble DNA sequences prepared in the same conditions (negative controls). For B95-8 proliferative model, high mobility group box 1 protein (HMGB1) was used as reference. Analyzed biological parameters on B95-8 were i) cell proliferation measured after 24 and $48 \mathrm{~h}$ of incubation with HD SNA and ii) expression of the EBV ZEBRA protein in response to TGF-B by Westernblotting $(\mathrm{T}+24 \mathrm{~h})$. For THP1 model, TNF-a synthesis and release were determined by RT-qPCR and ELISA (protein), after stimulation by LPS $(1 \mu \mathrm{g} / \mathrm{ml})$ and HD SNA co-administration.

Results: we demonstrated that HD SNA RA significantly down-regulated TNF-a synthesis and release. This biological activity was showed to be specific (no effect of HD scramble SNA) and related to the level of dilution (maximal effect with higher dilutions). Unexpectedly, a biological effect of agitated/diluted water was also detected in both cellular models. For B95-8 model, this effect resulted in a significant decrease of B95-8 proliferation (comparable to the HMGB1 reference) and an inhibition of ZEBRA expression. Similarly, a reproducible stimulation effect of HD water was obtained in the LPS-stimulated THP1 model.

Conclusions: these findings indicate that highly diluted SNA RA can regulate TNF- $\alpha$ synthesis and release by LPS-stimulated THP1 and support the hypothesis that these homeopathic preparations may act in modulating mRNA expression of the targeted genes. This in vitro work underlines the potential effect of agitated water in context of cellular models for testing biological properties of HD. 
Keywords: Specific Nucleic Acids (SNA®); Cellular models; Epstein-Barr virus, Tumor Necrosis Factor-a, Rheumatoid arthritis

\section{References:}

[1] Jenaer M, Henry MF, Garcia A, Marichal B. Evaluation of 2LHERP in preventing recurrences of genital herpes. Br Homeopath J. 2000 Oct;89(4):174-7.

\section{(c)) EY-NC-ND Licensed to GIRI}

Support: This project was supported by the Walloon Region (General Direction for Technologies, Research and Energy), Grant $n^{\circ} 5899$ and Labo'Life Belgium. Authors declare they had full access to all the data in this study and they take complete responsibility for the integrity of the data and the accuracy of the data analysis.

Conflict of interest: Ghada Alsaleh, Chloé Borde, Dominique Wachsmann, and Vincent Maréchal declare there is no conflict of interest. Etienne Capieaux and Pierre Dorfman are respectively Scientific Director and Medical Director at Labo'Life.

Received: 01 June 2012; Revised: 10 August 2012; Published: 30 September 2012.

Correspondence author: Pierre Dorfman, pierre.dorfman@wanadoo.fr

How to cite this article: Capieaux E, Alsaleh G, Borde C, Wachsmann D, Maréchal V, Dorfman P. Evaluation of biological activities of highly diluted nucleotide sequences by using cellular models. Int J High Dilution Res [online]. 2012 [cited YYYY Month dd]; 11(40):194-195. Proceedings of the XXVI GIRI Symposium; 2012 Sep 20-22; Florence (Italy). GIRI; 2012; Available from: http://www.feg.unesp.br/ ojs/index.php/ijhdr/article/view/608/604 